\title{
DECAY RESULTS FOR THE HEAT EQUATION UNDER RADIATION BOUNDARY CONDITIONS
}

\author{
L. E. PAYNE AND P. W. SCHAEFER
}

\begin{abstract}
The authors derive exponential decay bounds for the spatial derivatives of the solutions of some initial-boundary value problems for the heat equation in one and two space dimensions when linear radiation (Robin) conditions are prescribed on the boundary. Maximum principles for solutions of second order parabolic equations are used in deriving the results.
\end{abstract}

Mathematics subject classification (2000): 35K05, 35B50.

Key words and phrases: Heat equation, decay bounds, radiation condition.

\section{REFERENCES}

[1] K. A. Ames, L. E. PAYNe AND P. W. Schaefer, Spatial decay estimates in time dependent Stokes flow, SIAM J. Math. Anal. 24 (1993), 1395-1413.

[2] J. M. BALL, Remarks on blow-up and nonexistence theorems for nonlinear evolution equations, Quart. J. Math. Oxford 28 (1977), 473-486.

[3] J. P. G. EWER, On the asymptotic properties of a class of nonlinear parabolic equations, Appl. Anal. 13 (1982), 249-266.

[4] A. FRIEDMAN, Remarks on the maximum principle for parabolic equations and its applications, Pacific J. Math. 8 (1958), 201-211.

[5] C. O. Horgan AND L. T. WheEler, Spatial decay estimates for the heat equation via the maximum principle, ZAMP, 27 (1976), 371-376.

[6] C. O. Horgan, L. E. PAYNE, AND L. T. WheELER, Spatial decay in transient heat conduction, Q. Appl. Math. 42 (1984), 119-127.

[7] H. KIELHÖFER, Halbgruppen und semilineare Anfangs-randwert probleme, Manuscripta Math. 12 (1974), 121-152.

[8] L. NIRENBERG, A strong maximum principle for parabolic equations, Comm. Pure Appl. Math. 6 (1953), $167-177$.

[9] L. E. PAYNE AND G. A. PhILIPPIN, Decay bounds for solutions of second order parabolic problems and their derivatives, Math. Models and Meth. Appl. Sci. 5 (1995), 95-110; Corrigendum and addendum, 865-866.

[10] L. E. Payne And G. A. Philippin, Pointwise bounds and spatial decay estimate in heat conduction problems, Math. Models and Meth. Appl. Sci. 5 (1995), 755-775.

[11] L. E. PAYNE, P. W. SCHAEFER, AND J. C. SONG, Growth and decay results in heat conduction problems with nonlinear boundary conditions, Nonlinear Anal. 35 (1998), 269-286.

[12] G. A. PhILIPPIN AND S. VerniER-PIRO, Explicit exponential decay bounds in quasilinear parabolic problems, J. Ineq. and Appl. 3 (1999), 1-23.

[13] G. A. PhiLIPPIN AND S. VerniER-PIRO, Explicit decay bounds in some quasilinear one-dimensional parabolic problems, Math. Methods Appl. Sci. 22 (1999), 101-109.

[14] Y. SHENKER AND J. J. Roseman, On the exponential temporal decay of solutions and their derivatives for quasilinear parabolic equations, ZAMP 46 (1995), 198-223.

[15] R. P. SPERB, Maximum Principles and Their Applications, Math. in Sci. and Engr. vol 157, Academic Press, 1981. 